\title{
ANALISIS TINGKAT PENCEMARAN AIR DI KALI KAMPWOLKER SEBAGAI INLET KE PERAIRAN DANAU SENTANI DENGAN MENGGUNAKAN METODE POLLUTION INDEX
}

\author{
Auldry F. Walukow ${ }^{1}$, Triwiyono ${ }^{1}$ dan I Nyoman Sukarta ${ }^{2}$ \\ Jurusan PMIPA/Program Studi Pendidikan Fisika, Universitas Cenderawasih \\ Jayapura, Indonesia \\ 2Jurusan Kimia, Fakultas Matematika dan Ilmu Pengetahuan Alam, Universitas Pendidikan Ganesha \\ Bali, Indonesia \\ e-mail: auldrywalukow@yahoo.co.id, triwiyono07@yahoo.co.id, nyoman.sukarta@undiksha.ac.id
}

\begin{abstract}
Abstrak
Sungai Kampwolker terindikasi sudah mengalami pencemaran. Penelitian ini bertujuan untuk menganalisis tingkat pencemaran air di sungai Kampwolker menggunakan metode Pollution Index (PI). Hasil analisis mendapatkan nilai PI sebesar 6,470 artinya sungai Kampwolker telah tercemar sedang berdasarkan Klas II, sedangkan berdasarkan Klas I diperoleh nilai sebesar 7,534 juga tercemar sedang. Parameter - parameter yang tidak memenuhi baku mutu di sungai Kampwolker adalah DO, PO4, Zn, Cu, Hg, Fenol, Chlorine bebas, dan $\mathrm{Pb}$ dengan nilai konsentrasi berturut - turut $5,795 \mathrm{mg} / \mathrm{L} ; 1,705 \mathrm{mg} / \mathrm{L}$; 0,0665mg/L; 0,0245 mg/L; 0,08 mg/L; $13 \mu \mathrm{g} / \mathrm{L} ; 0,285 \mathrm{mg} / \mathrm{L} ;$ dan 0,078 mg/L.
\end{abstract}

Kata kunci: Sungai Kampwolker, tingkat pencemaran, Pollution Index.

\begin{abstract}
The Kampwolker River is indicated to have been polluted. This study aimed to analyze the level of water pollution in the Kampwolker river using the Pollution Index (PI) method. We calculated a PI value of 6.470 which indicated that the Kampwolker river was moderately polluted based on Class II; while based on Class I, we calculated a value of 7.534 which indicated that it was also moderately polluted. The parameters that did not meet the quality standards in the Kampwolker river were DO, PO4, $\mathrm{Zn}, \mathrm{Cu}, \mathrm{Hg}$, Phenol, free chlorine, and $\mathrm{Pb}$ with a concentration value of $5.795 \mathrm{mg} / \mathrm{L}, 1.705 \mathrm{mg} / \mathrm{L}, 0.0665 \mathrm{mg} / \mathrm{L}, 0.0245 \mathrm{mg} / \mathrm{L}, 0.08$ $\mathrm{mg} / \mathrm{L}, 13 \mu \mathrm{g} / \mathrm{L}, 0.285 \mathrm{mg} / \mathrm{L}$, and $0.078 \mathrm{mg} / \mathrm{L}$.
\end{abstract}

Keywords : Kampwolker River, pollution level, Pollution Index

\section{PENDAHULUAN}

Danau Sentani merupakan danau yang terletak di antara Kabupaten Jayapura dan Kota Jayapura Provinsi Papua. Danau tersebut merupakan salah satu sumberdaya alam yang sangat potensial jika dikelola dengan baik, diantaranya sumber air bersih, perikanan, dan pariwisata. Danau Sentani terletak di bagian timur laut Provinsi Papua, di sebelah barat Kota Jayapura. Kawasan Danau merupakan bagian dari kawasan lindung yang mencakup Kawasan Danau dan Cagar Alam Pegunungan Cycloop. Secara administratif wilayah ini termasuk dalam wilayah Kabupaten Jayapura dan Kota Jayapura, Provinsi Papua, secara geografis terletak antara $2^{0} 30^{\prime}-2^{0} 43^{\prime}$ LS dan $140^{\circ} 24^{\prime}$ - 140 $41^{\prime}$ BT. Luas Danau Sentani 9630 ha dan 650 ha berada pada wilayah administrasi Kota Jayapura (Kailola, 2016).

Sungai - sungai yang masuk (inlet)

ke Danau Sentani sebanyak 15 sungai, salah satunya adalah sungai Kampwolker. Sungai Kampwoker mempunyai panjang $13,01 \mathrm{~km}$ dengan debit sungai maksimum $383,40 \mathrm{~m}^{3} /$ detik dan mempunyai debit minimum sebesar $192,87 \mathrm{~m}^{3} /$ detik serta debit sedimen 8,22 gr/detik (Kailola, 2016).

Jurnal Sains dan Teknologi | 68 
Pada bagian hulu Sungai Kampwolker merupakan salah satu sumber air minum di kota Jayapura, sehingga sungai ini perlu dikelola agar tidak tercemar. Data menunjukkan bahwa sungai Kampwolker telah tercemar oleh beberapa parameter kimia oleh karena parameter parameter tersebut tidak memenuhi baku mutu. Parameter - parameter yang tidak memenuhi baku mutu di sungai Kampwolker seperti parameter DO, PO4, Zn, Cu, Hg, Fenol, Chlorine bebas, dan $\mathrm{Pb}$ dengan nilai konsentrasi berturut - turut $5,795 \mathrm{mg} / \mathrm{L}$; $1,705 \mathrm{mg} / \mathrm{L} ; 0,0665 \mathrm{mg} / \mathrm{L} ; 0,0245 \mathrm{mg} / \mathrm{L} ; 0,08$ $\mathrm{mg} / \mathrm{L} ; 13 \mu \mathrm{g} / \mathrm{L} ; 0,285 \mathrm{mg} / \mathrm{L} ;$ dan 0,078 mg/L (Kapisa, 2016). Parameter logam berat seperti $\mathrm{Hg}$ sangat berbahaya bagi tubuh manusia.

Beberapa penelitian tentang beban pencemaran sungai - sungai yang masuk ke Danau Sentani seperti beban pencemaran $\mathrm{Cu}$ di sungai Jembatan dua meningkat dari 0,01 ton/bulan menjadi 0,08 ton/bulan sejak tahun 2012 sampai 2014 (Walukow, 2016), beban pencemaran TDS meningkat dari 263,09 ton/bulan menjadi 287,70 ton/bulan (Walukow Auldry F ; DDjokosetiyanto;Kholil; Dedi Soedharma, 2008). Begitu pula beban pencemaran Posfat di Sungai Flafouw meningkat dari 0,26 ton/bulan menjadi 1,71 ton/bulan pada tahun 2005 sampai 2007 (Walukow, 2010). Peningkatan beban pencemaran di sungai - sungai yang masuk ke Danau Sentani tersebut telah mengakibatkan peningkatan sedimen di Danau Sentani. (Walukouw, 2017) dan (Walukow, 2017) juga telah meneliti pencemaran $\mathrm{Pb}$ dalam sedimen di Danau Sentani, dimana hasil penelitian menunjukkan bahwa konsentrasi $\mathrm{Pb}$ dalam sedimen sekitar $28 \mathrm{mg} / \mathrm{kg}$ sampai $40 \mathrm{mg} / \mathrm{kg}$.

Aktivitas - aktvitas di sekitar sungai Kampwolker berpotensi mencemari sungai tersebut, seperti pemukiman, industry/wirausaha, dan pertanian. Penelitian pencemaran sungai di luar negeri seperti (Yu et al., 2011) telah meneliti bahwa akibat kegiatan pertanian mempercepat transformasi pencemaran $\mathrm{N}$ ke sungai Lean dan akhirnya bermuara ke Danau Poyang. (Bosch, N. S.; Allan, J. D.; Dolan, D. M.; Han HaeJin; Richards, 2011) juga telah meneliti bahwa Pencemaran danau Erie disebabkan oleh tingginya debit sedimen di daerah aliran sungai Raisin, Maumee, Sandusky dan Grand, dan tingginya debit sedimen diprediksi dengan alat yang telah ditemukannya yaitu The Soil and Water Assessment Tool (SWAT). (Zhang et al., 2012) mengemukan bahwa untuk menurunkan beban pencemaran $\mathrm{NH}_{3}-\mathrm{N}$, TN dan TP dapat diterapkan metode management kualitas air dan model analisis yang dikembangkan adalah QUAL2K. Namun dalam penelitian - penelitian sebelumnya tersebut belum mengkaji status mutu air menggunakan metode Pollution Index (PI), sehingga tujuan penelitian ini adalah menganalisis tingkat pencemaran air di sungai Kampwolker menggunakan metode Pollution Index. Keunggulan metode ini adalah dapat diketahui status mutu air setiap tahun, sehingga akan membantu para pemerintah atau pengambil kebijakaan dalam upaya pengelolaan sungai Kampwolker.

\section{METODE}

Lokasi penelitian ini adalah Kali Kampwoker dengan koordinat LS.08 $28^{\circ} 52,7^{\prime}$ " dan BT. $140^{\circ} 26^{\prime} 08,8^{\prime \prime}$ dengan sumber data BPLH Propinsi (Kapisa, 2016). Penelitian ini berlangsung mulai bulan April sampai Juni 2019. Bahan yang dibutuhkan adalah data kualitas air sungai Kampwolker. Metode analisa data menggunakan metode Pollution Index $(\mathrm{Pl})$ dengan rumus sebagai berikut :

Lokasi sampling ditentukan secara purposive sampling dengan mempertimbangkan 1) tujuan pengambilan sampel, 2) jenis sumber air yang akan disampel, dan 3)pola aliran air badan air yang akan disampel, khususnya air permukaan. Posisi lokasi sampling ditentukan menggunakan Global Posisioning System. Parameter yang dikur adalah parameter Fisika dan Kimia.

Langkah - Langkah analisis :

Pertama, hitung $\mathrm{Ci} / \mathrm{Lij}$

Kedua, hitung Rata- rata $\mathrm{Ci} / \mathrm{Lij}$ dari semua parameter $=(\mathrm{Ci} / \mathrm{Lij})_{\mathrm{R}}$

Ketiga, hitung $\mathrm{Ci} / \mathrm{Lij}$ dari tiap parameter yang bernilai maksimum $=(\mathrm{Ci} / \mathrm{Lij})_{\mathrm{M}}$

Keempat, Hitung Pij berdasarkan rumus:

$\mathrm{Ci}=$ konsentrasi parameter kualitas air Hasil pengukuran

Jurnal Sains dan Teknologi | 69 
Lij= Baku mutu parameter kualitas air

$$
P I_{j}=\sqrt{\frac{\left(\frac{C_{i}}{L_{i j}}\right)_{m}^{2}+\left(\frac{C_{i}}{L_{i j}}\right)_{R}^{2}}{2}}
$$

Evaluasi Nilai IP :

$0 \leq \mathrm{Plj} \leq 1 \quad$ : Memenuhi Baku Mutu

$1<\mathrm{Plj} \leq 5 \quad$ : Cemar Ringan

$5<\mathrm{Plj} \leq 10:$ Cemar Sedang

Plj $\leq 5 \quad$ : Cemar Berat

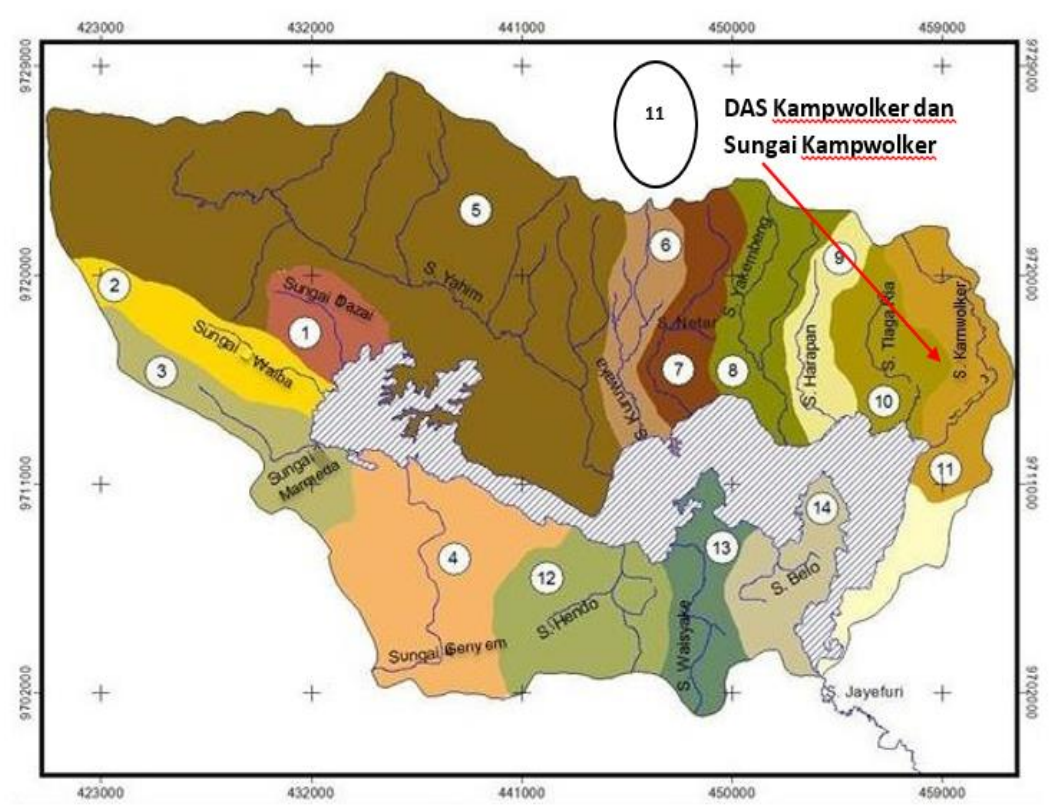

Gambar 1. Lokasi Penelitian

Tabel 1. Metode Analisis Sampel

\begin{tabular}{|c|c|c|c|}
\hline Number & $\begin{array}{l}\text { Parameter } \\
\text { Fisika }\end{array}$ & Satuan & Metode \\
\hline 1 & BOD & $\mathrm{mg} / \mathrm{L}$ & $\begin{array}{l}\text { Titrasi, } \\
\text { Laboratorium }\end{array}$ \\
\hline 2 & Fluoride & $\mathrm{mg} / \mathrm{L}$ & Spektometri \\
\hline 3 & Phospat & $\mathrm{mg} / \mathrm{L}$ & Spektometri \\
\hline 4 & Zinc & $\mathrm{mg} / \mathrm{L}$ & $\begin{array}{l}\text { Spektometri } \\
\text { serapan atom }\end{array}$ \\
\hline 5 & Copper & $\mathrm{mg} / \mathrm{L}$ & $\begin{array}{l}\text { Spektometri } \\
\text { serapan atom }\end{array}$ \\
\hline 6 & Mercury & $\mathrm{mg} / \mathrm{L}$ & $\begin{array}{l}\text { Spektometri } \\
\text { serapan atom }\end{array}$ \\
\hline 7 & Fenol & $\mathrm{mg} / \mathrm{L}$ & Spektometri \\
\hline 8 & $\begin{array}{l}\text { Free } \\
\text { Chlorine }\end{array}$ & $\mathrm{mg} / \mathrm{L}$ & Spektometri \\
\hline 9 & Lead Pb & $\mathrm{mg} / \mathrm{L}$ & $\begin{array}{l}\text { Spektometri } \\
\text { serapan atom }\end{array}$ \\
\hline
\end{tabular}

Metode pangambilan data yaitu data diambil pada kondisi cerah. Masing - masing lokasi sampling atau stasiun pengamatan dilakukan tiga kali ulangan. Pengambilan contoh air sampel menggunakan perahu. Parameter yang diukur meliputi sifat fisika dan kimia (Tabel 1).

\section{HASIL DAN PEMBAHASAN}

Hasil analisis dengan menggunakan metode Pollution Index diperoleh nilai PI sebesar 6,470 artinya sungai Kampwolker telah tercemar sedang berdasarkan Klas II, sedangkan berdasarkan Klas I sebesar 7,534 artinya juga tercemar sedang. Oleh karena tercemar sedang berdasarkan Klas II maka Sungai Kampwolker tidak layak untuk dimanfaatkan sebagai prasarana/sarana rekreasi, pembudidayaan ikan air tawar, peternakan, air untuk mengairi pertanaman. Penggunaan air untuk prasarana/sarana rekreasi seperti pemanfaatan untuk renang. Pemanfaatan untuk pembudidayaan ikan air tawar seperti untuk budidaya ikan di Danau Sentani. Pemanfaatan untuk peternakan seperti pemanfaatan air untuk ternak babi. 
Pemanfaatan air untuk mengairi pertanaman seperti untuk mengairi kolam kangkung. Penyebab tercemar sedang oleh karena ada beberapa parameter yang tidak memenuhi baku mutu yaitu parameter $\mathrm{BOD}, \mathrm{F}, \mathrm{PO}_{4}, \mathrm{Zn}$,
$\mathrm{Cu}, \mathrm{Hg}$, Fenol, Chlorine bebas, dan $\mathrm{Pb}$ dengan nilai konsentrasi berturut - turut 2,57 $\mathrm{mg} / \mathrm{L} ; 0,54 \mathrm{mg} / \mathrm{L} ; 1,705 \mathrm{mg} / \mathrm{L} ; 0,0665 \mathrm{mg} / \mathrm{L}$; $0,0245 \mathrm{mg} / \mathrm{L} ; 0,08 \mathrm{mg} / \mathrm{L} ; 13 \mu \mathrm{g} / \mathrm{L} ; 0,285$ mg/L; dan 0,078 mg/L (Gambar 2).

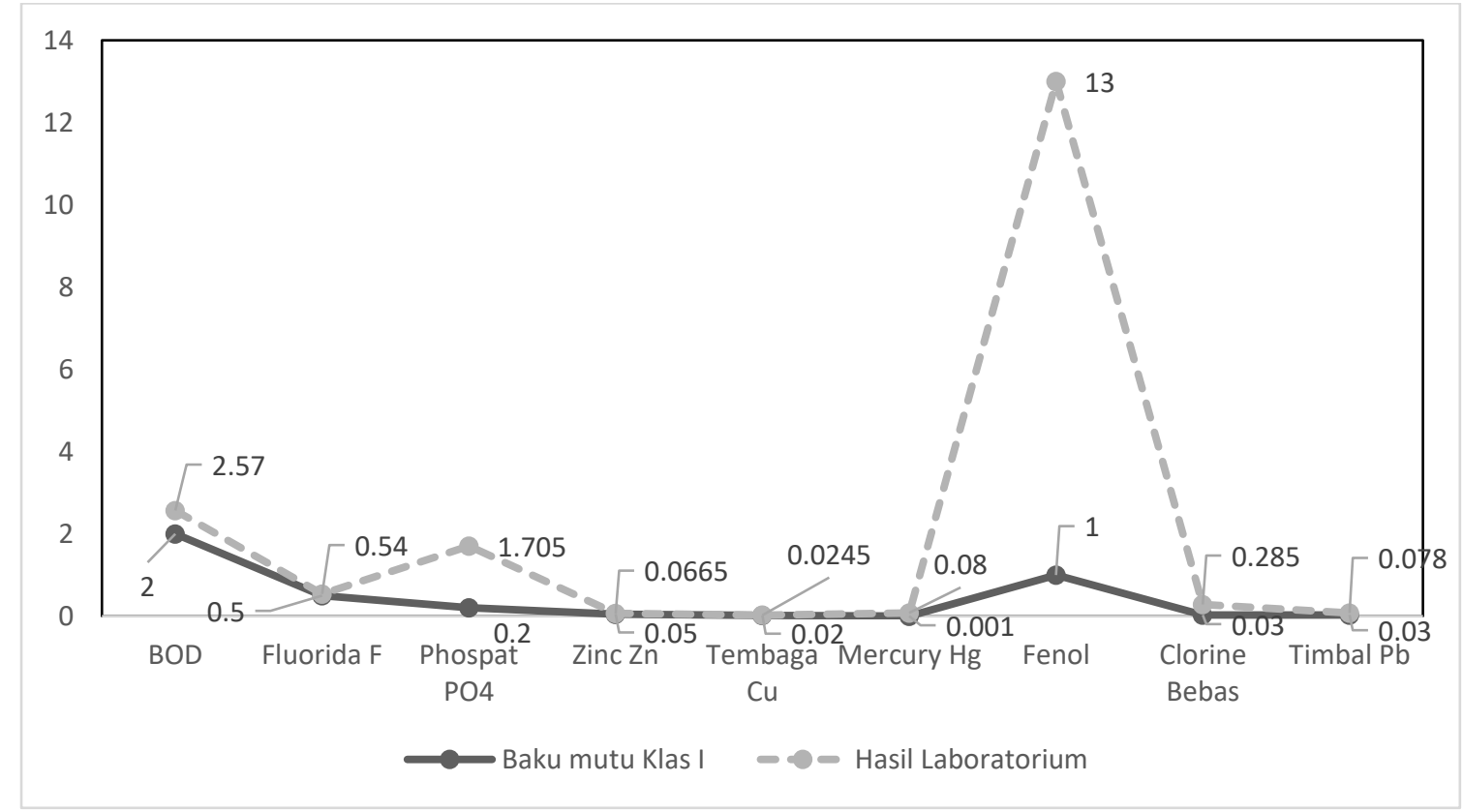

Gambar 2 Hasil Uji Laboratorium dan Baku Mutu

Hasil analisis juga menunjukkan bahwa Sungai Kampwolker tercemar sedang berdasarkan Klas I, maka air sungai tersebut tidak layak dimanfaatkan untuk air baku air minum. Air dapat menyebabkan sumber penyakit bagi manusia ketika mengkonsumsi air yang tercemar. Konsumsi air dengan kadar nitrat tinggi akan menimbulkan gangguan kesehatan seperti gondok, methemoglobinemia (darah kekurangan oksigen) dan sebagainya (Herlambang, 2006). Konsumsi ikan dari perairan yang tercemar mercury sangat berbahaya bagi kesehatan seperti kasus "Minamata disease" di Jepang yang mengakibatkan gejala keanehan mental dan cacat saraf (Setiyono, A., Djaidah, 2012). Konsumsi ikan atau air yang telah mengandung logam berat yang tinggi dapat menyebakan kemandulan, kerusakan jaringan organ tubuh, bahkan kematian. Sumber pencemaran air sungai Kampwolker kemungkinan disebakan oleh alih fungsi lahan yang tidak terkontrol, limbah domestic, limbah bengkel oli, limbah cucian motor dan mobil, limbah cucian laundry, dan limbah oli
PLTD atau secara alami sumber pencemaran berasal dari erosi dan air hujan. Alih fungsi lahan di sekitar sungai Kampwolker dan Cagar alam Cycloop yaitu alih fungsi lahan menjadi lahan pertanian dan pemukiman. Padahal peruntukan lahan di Cagar alam Cycloop adalah hutan lindung dan daerah resapan air dan bukan dimanfaatkan untuk lahan pertanian dan pemukiman. (Chakraborty, C., Huq, M.M., Ahmed, S., Tabassum, T., Miah, 2013) juga menyebutkan bahwa sumber pencemaran secara alami adalah karena kematian hewan dan tumbuhan yang akhirnya memasuki perairan sungai, sedangkan limbah domestic dan limbah industry merupakan sumber pencemaran karena aktivitas manusia. (Dwivedi, 2017) mengemukakan bahwa sumber - sumber pencemaran air adalah pemukiman, industry, air larian permukaan kegiatan pertanian. Laju erosi di DAS Expo (DAS Kampwolker) meningkat dari tahun 2007 sampai 2012 yaitu dari 86596,594 $\mathrm{m}^{3} /$ tahun menjadi 96739,224 $\mathrm{m}^{3}$ /tahun (Kapisa, 2017). Hasil penelitian ini sejalan dengan kajian (Amira, S., Astono, 
W., Hendrawan, 2018) yang menyimpulkan bahwa sungai Grogol tercemar ringan pada musim hujan dan tercemar sedang pada musim kemarau, informasi yang diperoleh dalam penelitian ini dapat digunakan oleh pengambil kebijakan untuk peningkatan kualitas sungai Grogol. Namun hal yang unik terjadi di Sungai Code, Sungai Winongo,dan sungai Gadjah Wong dimana tingkat pencemaran air tidak selalu menurun pada musim hujan tetapi justru mengalami peningkatan (Saraswati et al., 2019). Hal tersebut disebabkan oleh aktivitas hotel, malls, restaurant, pabrik bakeries, pencusian motor/mobil, livestock industry, gas station, railway station, jasa layanan kesehatan (puskesmas, rumah sakit), industry percetakan, salon kecantikan, industry tempe, idustri batik, industry pemotongan ayam, industry farmasi (obat), laundry, industry mobil yang berlokasi di sekitar daerah tangkapan air sungai Code, Sungai Winongo,dan sungai Gadjah Wong. Jadi pencemaran sungai disebabkan oleh aktivitas - aktivitas di sekitar sungai, baik aktivitas di hulu dan di hilir sungai. Aktivitas di Industri dan pemukiman sering membuang limbah padat ke sungai seperti yang terjadi di Sungai Shankila di kota Addis Ababa, yang menyebabkan air sungai tidak dapat diminum oleh karena tidak memenuhi standar WHO (Tarekegn \& Truye, 2018). Pencemaran sungai banyak terjadi di luar negeri seperti yang terjadi di kota Dhaka tepatnya di ibu kota dari negara Bangladesh, hasil analisis menunjukkan bahwa kualitas air sungai Turag tidak mampu mendukung kehidupan di perairan dan tidak mendukung untuk kebutuhan air minum untuk pemukiman. Dimana konsentrasi parameter kekeruhan, BOD, TDS, dan COD di sungai Turag telah melebihi standar baku mutu yang diijinkan (Halder \& Islam, 2015). Jadi air memainkan peranan penting dalam kehidupan manusia, jika air telah tercemar maka tidak dapat dikonsumsi lagi oleh manusia dan mahluk hidup lain. Pengelolaan kualitas air dan pengendalian pencemaran air sungai Kampwolker perlu diimplementasikan secara terpadu dengan pendekatan ekosistem. Keterpaduan ini dimaksudkan mulai dari perencanaan, pelaksanaan, pengawasan dan evaluasi
(Pengelolaan Kualitas Air Dan Pengendalian Pencemaran Air, 2001). Konsep pembangunan berkelanjutan adalah mengelola sumberdaya alam untuk kepentingan ekonomi masyarakat saat ini, tetapi perlu meninggalkan sumberdaya alam yang baik bagi generasi yang akan datang. Hal ini dapat terwujud jika ada keseimbangan dan optimalisasi dalam pembangunan ekonomi, social dan ekologi. Keserakahan manusia mengakibatkan tidak ada keseimbangan antara system social, ekonomi dan lingkungan, dan hal ini mengakibatkan terjadinya degradasi lingkungan hidup. Manusia cenderung hanya mengedepankan pembangunan ekonomi namun tidak memperhatikan system lingkungan dan system social, hal inilah yang disebut sebagai antropocentris dan bukan ecocentris. Pengelolaan kualitas air sungai harus segera ditangani karena akan berdampak pada system social, system ekonomi dan system ekologi. (Bhuiyan et al., 2015) mengemukakan bahwa pencemaran air membawa resiko pada lingkungan yaitu pada system ekologi, social dan ekonomi di sekitar Daerah aliran sungai (DAS). Pencemaran air disebabkan oleh tidak terwujudnya konsep pembangunan berkelanjutan oleh karena terjadinya perubahan ekosistem, perubahan tutupan lahan, kerusakan lingkungan dan akhirnya pencemaran air yang menyebabkan degradasi biodiversity dan geodiversity. Sehingga dapat disimpulkan bahwa aktivitas manusia dan pola penggunaan lahan yang tidak terkontrol berpengaruh signifikan terhadap terjadinya pencemaran air sungai (Vadde, K. K., Wang, J., Cao, L., Yuan, T., McCarthy, A. J., Sekar, 2018).

\section{SIMPULAN}

Hasil analisis dengan menggunakan metode Pollution Index diperoleh nilai PI sebesar 6,470 artinya tingkat pencemaran sungai Kampwolker telah tercemar sedang berdasarkan Klas II, sedangkan berdasarkan Klas I sebesar 7,534 juga tercemar sedang. Pencemaran yang terjadi di Sungai Kampwolker disebabkan oleh akitivitas manusia. Pengelolaan kualitas air dan pengendalian pencemaran air sungai Kampwolker perlu diterapkan secara Jurnal Sains dan Teknologi | 72 
terpadu dengan mengedepankan keseimbangan dalam aspek social, ekonomi dan lingkungan, serta perlu optimalisasi pemanfaatan sumberdaya alam yang tertuang dalam konsep pembangunan berkelanjutan.

\section{UCAPAN TERIMAKASIH}

Ucapan terimakasih ditujukan kepada LPPM Uncen dan DRPM DIKTI sebagai penyandang dana atau telah memberikan kontribusi dana dalam penelitian ini.

\section{DAFTAR PUSTAKA}

Amira, S., Astono, W., Hendrawan, D. (2018). Study of pollution effect on water quality of Grogol River , DKI Jakarta Study of pollution effect on water quality of Grogol River , DKI Jakarta. Journal Earth and Environmental Science, 106, 1-6.

Bhuiyan, A. B., Mokhtar, M. B., Toriman, M. E., Gasim, M. B., Ta, G. C., Elfithri, R., \& Razman, M. R. (2015). The Environmental Risk And Water Pollution: A Review From The River Basins Around The World. Journal of Sustainable Agriculture, 7(2), 126-136.

Bosch, N. S.; Allan, J. D.; Dolan, D. M.; Han HaeJin; Richards, R. P. (2011). Application of the Soil and Water Assesssment Tool for six watersheds of Lake Erie: Model parameterization and calibration, United States. Journal of Great Lakes Research, 37(2), 263271.

Chakraborty, C., Huq, M.M., Ahmed, S., Tabassum, T., Miah, M. R. (2013). Analysis Of The Causes And Impacts Of Water Pollution Of Buriganga River: A Critical Study. Journal Of Scientific 7 Technology Research, 2(9), 245-252.

Dwivedi, A. K. (2017). (C) Associated Asia Research Foundation ( AARF ) RESEARCHES IN WATER POLLUTION : A REVIEW. International Research Journal Of Natural and Applied Sciences (IRJNAS), 4(January), 118-142. https://doi.org/10.13140/RG.2.2.12094. 08002

Halder, J. N., \& Islam, M. N. (2015). Water Pollution and its Impact on the Human Health. Journal Of Environment and
Human, 2(1), 36-46. https://doi.org/10.15764/EH.2015.0100 5

Herlambang, A. (2006). Pencemaran air dan strategi penggulangannya. Jurnal JAI, 2(1), 16-29.

Kailola, K. (2016). Status Lingkungan Hidup Daerah Kota Jayapura. Pemerintah Kota Jayapura (1 (ed.)). DLHK Kota Jayapura.

Kapisa, N. (2016). Laporan Pemantauan Kualitas Air Propinsi Papua. BPLH Propinsi Papua.

Kapisa, N. (2017). Kondisi Kenaikan Permukaan Danau Sentani 2016-2017. BPLH Propinsi Papua.

Pengelolaan Kualitas Air Dan Pengendalian Pencemaran Air, (2001).

Saraswati, S. P., Ardion, M. V., Widodo, Y. H., \& Hadisusanto, S. (2019). Water Quality Index Performance for River Pollution Control Based on Better Ecological Point of View ( A Case Study in Code, Winongo, Gadjah Wong Streams ). Journal of The Civil Engineering Forum, 5(1), 47-56.

Setiyono, A., Djaidah, A. (2012). Konsumsi Ikan dan Hasil Pertanian Terhadap Kadar Hg Darah. Jurnal Keseharan Masyarakat, 7(2), 110-116.

Tarekegn, M. M., \& Truye, A. Z. (2018). Causes and impacts of shankila river water pollution in Addis Ababa , Ethiopia . 2(4).

Vadde, K. K., Wang, J., Cao, L., Yuan, T., McCarthy, A. J., Sekar, R. (2018). Assessment of Water and Identification of Pollution Risk Locations in Tiaoxi River (Taihu Watershed). Journal Water, 10(183), 1-8.

Walukouw, A. F. (2017). Analysis of Pb Levels as Pollutant in the Waters of the Sentani Lake, Jayapura- Indonesia : Study of Determining Water Quality. Journal Der Pharma Chemica, 9(18), 6-8.

Walukow, A. F. (2010). Kajian Parameter Kimia Posfat Di Perairan Danau Sentani Berwawasan Lingkungan. Jurnal Forum Geografi, 24(2), 183197.

Walukow, A. F. (2016). Analysis of metal concentrations of copper ( $\mathrm{Cu}$ ) in 
water at sentani lake in jayapurapapua. Journal Der Pharmacia Lettre, 8(2), 303-308.

Walukow, A. F. (2017). Analysis of Pollution on Physical-Chemical Parameters and Waters Environmental Quality Index Using Storet Index in Natural Tourism Park at Youtefa Bay, Jayapura, Indonesia. Journal Der Pharma Chemica, 9(9), 8-12.

Walukow Auldry F ; DDjokosetiyanto;Kholil; Dedi Soedharma. (2008). Analisis Beban Pencemaran dan Kapasitas Asimilasi [ Analysis the Pollution Load and the Assimilation Capacity of Lake Sentani , Papua for Conservation of Aquaculture Environment ]. Jurnal Berita Biologi, 9(3), 229-236.

Yu, X., Lingguang, H., \& Ligang, X. (2011). Characteristics of Diffuse Source $N$ Pollution in Lean River Catchment. 10(Esiat), 2437-2443. https://doi.org/10.1016/j.proenv.2011.0 9.379

Zhang, R., Qian, X., Yuan, X., Ye, R., Xia, B., \& Wang, Y. (2012). Simulation of Water Environmental Capacity and Pollution Load Reduction Using QUAL2K for Water Environmental Management. 4504-4521. https://doi.org/10.3390/ijerph9124504 